\title{
Pregnant and active - suitability of the Pregnancy Physical Activity Questionnaire for measuring the physical activity of pregnant women in Poland
}

\author{
JUSTYNA KRZEPOTA ${ }^{1, A-F}$, DOROTA SADOWSKA ${ }^{2, C-F}$
}

${ }^{1}$ Department of Physical Culture and Health Promotion, University of Szczecin, Szczecin

${ }^{2}$ Department of Physiology, Institute of Sport-National Research, Warsaw

A - Study Design, B - Data Collection, C - Statistical Analysis, D - Data Interpretation, E - Manuscript Preparation, F - Literature Search, G - Funds Collection

Summary Background. The issue of physical activity of pregnant women, including determining proper recommendations, has been a broadly discussed topic in international circles.

Objectives. The aim of this paper is to present the suitability of the Pregnancy Physical Activity Questionnaire (PPAQ) for measuring the physical activity of pregnant women in Poland.

Material and methods. The study included 162 questionnaires, which were filled in correctly by pregnant women (third trimester) who took part in childbirth classes organized by a childbirth school. As a research method, the PPAQ was chosen. The PPAQ allows pregnant women to self-assess their physical activity in the current trimester. The questions investigated time devoted to various types of activity related to household/caregiving, transportation, sports/exercise in their free time, occupational activity and inactivity. Based on the average weekly energy expenditure, each of these activities is classified by intensity: sedentary activity, light-intensity activity, moderate-intensity activity, vigorous-intensity activity.

Results. While using the PPAQ in Poland, it is recommended to reduce the number of questions from 36 to 35 , by removing question 18 (time of mowing lawn while on a riding mower). It is also advisable to convert American units of measurement into metric units, which are used in Poland.

Conclusions. The Pregnancy Physical Activity Questionnaire in Poland may fill the gap in studies devoted to the physical activity of pregnant Polish women. With this questionnaire, it is possible to determine energy expenditure in terms of intensity and type of physical activity. It also serves as a reliable tool that can be used for international comparisons.

Key words: pregnancy, physical activity, health promotion, questionnaire, woman, PPAQ.

Krzepota J, Sadowska D. Pregnant and active - suitability of the Pregnancy Physical Activity Questionnaire for measuring the physical activity of pregnant women in Poland. Fam Med Prim Care Rev 2017; 19(1): 29-33, doi: 10.5114/fmpcr.2017.65094.

\section{Background}

Nowadays, preventive healthcare is one of the most widely discussed issues related to the health of pregnant women [1]. The holistic approach to human health and disease prevention has become an interdisciplinary issue faced by specialists from numerous fields of science. The health of pregnant women and their babies is currently a goal which needs to be attained not only during pregnancy, but even at the stage of planning one's pregnancy.

To ensure the health of pregnant women, a combination of the following factors needs to be observed: folic acid supplementation [2], omega-3 fatty acid supplementation [3], healthy nutrition [4], dental health [5], depression prevention [6], alcohol consumption prevention [7], smoking prevention [8], as well as taking up physical activity [9]. The issue of physical activity of pregnant women, including determining proper recommendations, has been a broadly discussed topic in international circles [10]. Nowadays, medical advances and broader knowledge based on extensive research have resulted in general acceptance and appreciation for physical activity during pregnancy [11]. Currently, doctors around the world present guidelines on the intensity and duration of physical activity, provided there are no medical contraindications and the woman consults the issue with her doctor $[10,12]$. One of benefits of physical activity during pregnancy is a reduced risk of gestational diabetes [13]; nevertheless, the level of knowledge in Polish women about gestational diabetes is still insufficient [14]. Physical activity helps control body mass and prevents obesity [15], which increases perinatal mortality [16]. Additionally, physically active women tend to experience fewer side effects of pregnancy, such as insomnia, anxiety and somatic symptoms (e.g. fatigue, heartburn, nausea, leg cramps and edema) [17]. It has also been noted that properly selected and safe physical exercises do not increase the risk of premature birth [18]. Nevertheless, literature points to many obstacles, fears and barriers that discourage women from physical activity during pregnancy $[19,20]$.

It is especially important to investigate the current level of physical activity of pregnant women in order to popularize promotional activities and organize social campaigns aimed at creating proper prevention programs, changing awareness and encouraging women to be active while pregnant.

Conducting population-based research in terms of the physical activity of pregnant women in Poland is currently a challenging task, because there is no single, commonly used tool targeted solely at pregnant women. Therefore, this paper aims at presenting the Pregnancy Physical Activity Questionnaire as a tool to measure the physical activity of pregnant women in Poland, as well as determining whether it can be used in Poland. 


\section{Material and methods}

\section{Participants}

The study included 162 questionnaires filled in correctly by pregnant women (third trimester) who took part in childbirth classes organized by a childbirth school in Szczecin, Poland. The questionnaire was completed only by pregnant women who voluntarily agreed to participate in this research. 200 questionnaires were distributed to women, only 162 of which were fully and properly completed. 12 questionnaires were incompletely or incorrectly filled in, and 26 questionnaires were not returned. Respondents were $29.3 \pm 3.5$ years old. $88 \%$ of them completed college, $11 \%$ high school and $1 \%$ elementary school. The vast majority (91\%) were from Szczecin, while 9\% lived in the surrounding area. $83 \%$ of the subjects were married, $15 \%$ were single, while $2 \%$ were divorced. $90 \%$ were childless, and $10 \%$ had 1 child. The permission of the Bioethics Committee to conduct the research was obtained.

\section{Research method}

As a research method, the Pregnancy Physical Activity Questionnaire (PPAQ) was selected, which was designed by Chasan-Taber et al. [21]. This allows pregnant women to self-assess their physical activity in the current trimester. All subjects completed the questionnaire independently. Originally, the questionnaire contained 36 questions.

The first 3 questions related to personal data, and the remaining 33 questions investigated time devoted to various types of activity related to:

1) household/caregiving -13 questions,

2) transportation -3 questions,

3) sports/exercise in their free time -9 questions,

4) occupational activity -5 questions,

5) inactivity -3 questions.

Additionally, at the end of the sports/exercise section of the PPAQ, two open-ended questions allowed the respondent to add any activities not previously listed.

Respondents needed to choose one of the suggested time ranges per day:

- none, less than $1 / 2$ hour per day, $1 / 2$ to almost 1 hour per day, 1 to almost 2 hours per day, 2 to almost 3 hours per day, 3 or more hours per day (questions: 4,5 , $6,7,8,9,10,11,14,15,16,19,20,21)$;

- none, less than $1 / 2$ hours per day, $1 / 2$ to almost 2 hours per day, 2 to almost 4 hours per day, 4 to almost 6 hours per day, 6 or more hours per day (questions: $12,13,31,32,33,34,35$ );

as well as choose one of the suggested categories for activities carried out every week:

- none, less than $1 / 2$ hour per week, $1 / 2$ to almost 1 hour per week, 1 to almost 2 hours per week, 2 to almost 3 hours per week, 3 or more hours per week (questions: $17,18,22,23,24,25,26,27,28,29,30$ ).

Based on the average weekly energy expenditure, each of these activities was additionally classified by intensity:

a) sedentary activity,

b) light-intensity activity,

c) moderate-intensity activity,

d) vigorous-intensity activity.

The questionnaire helped measure average weekly energy expenditure related to total activity in MET units (MET-h/week). To calculate the energy expenditure for a given activity, the time devoted to the activity is multiplied by the intensity level assigned to it. Calculations were conducted according to the in- structions provided by the authors of the questionnaire [22], which included MET values for all activities.

Having obtained the permission of the PPAQ's author [21], the first stage of adapting the questionnaire to Polish realities was to translate it into Polish (forward translation) by two independent native Polish translators proficient in English. Next, one reconciled Polish version of the questionnaire was approved. The next stage was back-translation, which was meticulously provided by two independent native-English translators. The back-translated versions were deemed consistent with the original version. Finally, the most linguistically correct Polish version of the questionnaire was approved.

\section{Results}

Table 1 presents the original questions in the PPAQ. Each activity was classified by type and intensity.

There were 13 questions related to household/caregiving activity -6 of them were considered light-intensity activities and 7 moderate-intensity activities. Having analyzed all questions and responses given by the subjects in this section of the questionnaire, it was decided that in Poland, question 18 should be omitted (time of mowing lawn while on a riding mower).

There were 3 questions related to transportation activity, two of which were light-intensity activities, and one was moderate-intensity activity. Having analyzed all questions and responses given by the subjects in this section of the questionnaire, it is proposed that no question should be omitted.

There were 9 questions related to sports/exercise activity, five of which were moderate-intensity activities, and two were vigorous-intensity activities. Additionally, there were two openended questions $\left({ }^{*}\right)$, which allowed the respondent to add any activities not previously listed. Their intensity should be verified and calculated according to the guidelines in the Compendium of Physical Activities [22]. Having analyzed all questions and responses given by the subjects in this section of the questionnaire, it is proposed that no question should be omitted in Poland.

Occupational activity section was completed only by respondents in paid employment, those who worked as volunteers or those who studied. If the respondent was a housewife, unemployed or unable to work, she did not fill in that section of the questionnaire. This section included 5 questions, 3 of which were light-intensity activities, and two were moderate-intensity activities. To adjust the questionnaire to Polish realities, in questions 33 and 35, it is recommended to convert American measurement units into metric units, which are used in Poland, and ' 1 gallon' should be replaced with ' 4 liters'. Having analyzed all questions and responses given by the subjects in this section of the questionnaire, it is proposed that no question should be omitted in Poland.

Additionally, there were 3 questions in the questionnaire related to inactivity. One of these related to light-intensity activity, and the remaining two to sedentary activities. It is proposed to keep all these questions in the Polish version of the questionnaire as well.

Table 2 presents particular results based on the Pregnancy Physical Activity Questionnaires (PPAQs) by activity intensity and type among 162 pregnant women.

As results from the presented values, the median for total activity of surveyed women was $246.41 \mathrm{MET}$-h/week. Taking into account the activity as far as the level of intensity is concerned, women obtained the highest median (153.91 MET-h/ week) for moderate activity. In turn, taking into consideration the type of activity, the highest energy expenditure was obtained by the surveyed women within the activity of household/ caregiving (Mdn = 69.04 MET-h/week). 


\begin{tabular}{|c|c|c|c|c|}
\hline Activity & Question no. & Intensity & Questionnaire question content & $\begin{array}{l}\text { Question modified/ } \\
\text { kept in Polish version }\end{array}$ \\
\hline \multirow{13}{*}{$\begin{array}{l}\text { Household/care } \\
\text { giving activity }\end{array}$} & 4 & L & Preparing meals (cook, set table, wash dishes) & no/yes \\
\hline & 5 & L & Dressing, bathing, feeding children while you are sitting & no/yes \\
\hline & 7 & $\mathrm{~L}$ & Playing with children while you are sitting or standing & no/yes \\
\hline & 15 & L & Light cleaning (make beds, laundry, iron, put things away) & no/yes \\
\hline & 16 & L & Shopping (for food, clothes, or other items) & no/yes \\
\hline & 17 & $\mathrm{~L}$ & Heavier cleaning (vacuum, mop, sweep, wash windows) & no/yes \\
\hline & 18 & L & Mowing lawn while on a riding mower & $-/$ no \\
\hline & 6 & $\mathrm{M}$ & Dressing, bathing, feeding children while you are standing & no/yes \\
\hline & 8 & M & Playing with children while you are walking or running & no/yes \\
\hline & 9 & $M$ & Carrying children & no/yes \\
\hline & 10 & M & Taking care of an older adult & no/yes \\
\hline & 14 & M & Playing with pets & no/yes \\
\hline & 19 & M & Mowing lawn using a walking mower, raking, gardening & no/yes \\
\hline \multirow[t]{3}{*}{ Inactivity } & 11 & $\mathrm{~L}$ & Sitting and using a computer or writing, while not at work & no/yes \\
\hline & 12 & $\mathrm{~S}$ & Watching TV or a video & no/yes \\
\hline & 13 & S & $\begin{array}{l}\text { Sitting and reading, talking, or on the phone, while not at } \\
\text { work }\end{array}$ & no/yes \\
\hline \multirow[t]{3}{*}{$\begin{array}{l}\text { Transportation } \\
\text { activity }\end{array}$} & 20 & L & $\begin{array}{l}\text { Walking slowly to go places (such as to the bus, work, visit- } \\
\text { ing). Not for fun or exercise }\end{array}$ & no/yes \\
\hline & 22 & $\mathrm{~L}$ & Driving or riding in a car or bus & no/yes \\
\hline & 21 & $M$ & $\begin{array}{l}\text { Walking quickly to go places (such as to the bus, work, or } \\
\text { school). Not for fun or exercise }\end{array}$ & no/yes \\
\hline \multirow{9}{*}{$\begin{array}{l}\text { Sports/exercise } \\
\text { activity }\end{array}$} & 23 & M & Walking slowly for fun or exercise & no/yes \\
\hline & 24 & $M$ & Walking more quickly for fun or exercise & no/yes \\
\hline & 27 & $\mathrm{M}$ & Prenatal exercise class & no/yes \\
\hline & 28 & $\mathrm{M}$ & Swimming & no/yes \\
\hline & 29 & $\mathrm{M}$ & Dancing & no/yes \\
\hline & 25 & $\mathrm{~V}$ & Walking quickly up hills for fun or exercise & no/yes \\
\hline & 26 & $\mathrm{~V}$ & Jogging & no/yes \\
\hline & 30 & $*$ & $\begin{array}{l}\text { Doing other things for fun or exercise? Please tell us what } \\
\text { they are }\end{array}$ & no/yes \\
\hline & 31 & $*$ & $\begin{array}{l}\text { Doing other things for fun or exercise? Please tell us what } \\
\text { they are }\end{array}$ & no/yes \\
\hline \multirow{5}{*}{$\begin{array}{l}\text { Occupational } \\
\text { activity }\end{array}$} & 32 & $\mathrm{~L}$ & Sitting at work or in a class & no/yes \\
\hline & 34 & $\mathrm{~L}$ & Standing or slowly walking at work not carrying anything & no/yes \\
\hline & 33 & $M$ & $\begin{array}{l}\text { Standing or slowly walking at work while carrying things } \\
\text { (heavier than a } 1 \text { gallon milk jug) }\end{array}$ & yes/yes \\
\hline & 35 & M & $\begin{array}{l}\text { Walking quickly at work while carrying things (heavier than } \\
\text { a } 1 \text { gallon milk jug) }\end{array}$ & yes/yes \\
\hline & 36 & M & Walking quickly at work not carrying anything & no/yes \\
\hline
\end{tabular}

L - Light-intensity activity, M - moderate-intensity activity, V - vigorous-intensity activity, S - sedentary activity; * intensity according to the Compendium of Physical Activities [22].

\begin{tabular}{|c|c|c|c|}
\hline \multirow[t]{2}{*}{ PPAQ Measures } & \multicolumn{3}{|c|}{ PPAQ $1^{\text {st }}$ (MET-h/week) } \\
\hline & $25^{\text {th }}$ & Median & $75^{\text {th }}$ \\
\hline \multicolumn{4}{|l|}{ Summary activity stores: } \\
\hline Total activity & 204.48 & 246.41 & 318.25 \\
\hline Total activity of light intensity and above & 152.35 & 198.26 & 259.79 \\
\hline \multicolumn{4}{|l|}{ By intensity: } \\
\hline Sedentary (<1.5 METs) & 30.63 & 44.63 & 65.10 \\
\hline Light $(1.5-<3.0 \mathrm{METs})$ & 122.50 & 153.91 & 191.63 \\
\hline Moderate (3.0-6.0 METs) & 22.66 & 44.39 & 81.48 \\
\hline Vigorous (> 6.0 METs) & 0.00 & 0.00 & 1.63 \\
\hline
\end{tabular}




\begin{tabular}{|c|c|c|c|}
\hline \multirow[t]{2}{*}{ PPAQ Measures } & \multicolumn{3}{|c|}{ PPAQ $1^{\text {st }}$ (MET-h/week) } \\
\hline & $25^{\text {th }}$ & Median & $75^{\text {th }}$ \\
\hline \multicolumn{4}{|l|}{ By type: } \\
\hline Household/caregiving & 54.60 & 69.04 & 98.67 \\
\hline Occupational activity & 0.00 & 0.00 & 71.05 \\
\hline Sports/exercise & 7.20 & 13.78 & 25.01 \\
\hline Transportation & 28.22 & 51.63 & 91.00 \\
\hline Inactivity & 42.18 & 64.31 & 83.48 \\
\hline
\end{tabular}

\section{Discussion}

The aim of this study was to present the suitability of the Pregnancy Physical Activity Questionnaire for measuring the physical activity of pregnant women in Poland. Measuring physical activity is a complex issue; therefore, using a questionnaire as a research tool (despite its limitation) remains the most common method employed in population-based studies.

International authors tend to use various questionnaires to assess pregnant women's physical activity [21, 23-26]. Some of them are targeted solely at pregnant women, e.g. the Pregnancy Physical Activity Questionnaire (PPAQ) [21] or the Third Pregnancy Infection and Nutrition Study (PIN3) Physical Activity Questionnaire [23]. The PPAQ provides data on physical activity and actions taken during the current trimester, while the PIN3 measures the physical activity of pregnant women during the week before the research. Some researchers utilized popular physical activity questionnaires used for measuring activity in the last 7 days before the study amongst the general population, i.e. International Physical Activity Questionnaire (IPAQ) [24, 25], while others modified it [26] to include only questions related to forms of leisure and household chores within the past two weeks. Furthermore, there are publications which analyze the suitability of general questionnaires for assessment of physical activity, e.g. Kaiser Physical Activity Survey [27], among pregnant women. Undoubtedly, the variety of questions and scales of measurement make it harder to interpret and compare the results of different questionnaires.

In recent years, the most commonly used tool has been the Pregnancy Physical Activity Questionnaire (PPAQ), which was adapted and assessed in terms of reliability by researchers who worked on Vietnamese, Japanese and French versions [28-33]. Due to cultural differences in all these countries, minor changes were implemented in the final versions of the questionnaires [28-33]. Similarly to the Polish version, in both the Vietnamese and French versions, question about mowing lawn while on a riding mower was additionally omitted, and measurement units were converted to facilitate the comprehension of questions. In Poland, gallons of milk could be replaced by liters of milk, while in the Japanese version, ' $3 \mathrm{~kg}$ of rice' was proposed as a replacement.

\section{Conclusions}

Taking into account the need to increase the consciousness and promotion of health-related behaviors of pregnant women in Poland, the present suggestion to use the PPAQ with a slight modification seems to be relevant in this issue. This is indicated that in the assumptions of the modern health care there are important health promotion and disease prevention programs which include a measurement of health-related behaviors and inhibit the progression of chronic disease and the incidence of complications [34].

It is worth noting that in Poland, the International Physical Activity Questionnaire is generally accepted and widely used in the assessment of physical activity [35]. Nevertheless, it should be noted that due to increasing international popularity of the Pregnancy Physical Activity Questionnaire and lack of prevalent tool in Poland to measure the physical activity of pregnant women, the authors feel that the PPAQ may help fill the gap in Polish research on the physical activity of pregnant women. In the Polish version of the questionnaire, it is recommended to reduce the number of questions from 36 to 35 (by omitting question 18) and convert American measurements into the metric system, which is used in Poland. One of the advantages of the PPAQ is its meticulous and conscientious preparation in terms of guidelines for analyzing results, as well as its attractive visual form, which facilitates the task for respondents. Using the questionnaire in Poland may help assess the energy expenditure of pregnant women, based on intensity or type of activity, as well as enable international comparisons.

Source of funding: This work was funded from the Department of Physical Culture and Health Promotion University of Szczecin funds for statutory research and from the authors' own resources.

Conflict of interest: The authors declare no conflict of interests.

\section{References}

1. Pearce EE, Evenson KR, Downs DS, et al. Strategies to promote physical activity during pregnancy: a systematic review of intervention evidence. Am J Lifestyle Med 2013; 7(1), doi: 10,1177/1559827612446416.

2. Scholl TO, Johnson WG. Folic acid: influence on the outcome of pregnancy. Am J Clin Nutr 2000; 71(5): 1295-1303.

3. Jordan RG. Prenatal omega-3 fatty acids: review and recommendations. J Midwifery Womens Health 2010; 55(6): 520-528.

4. Kaiser L, Allen LH. Position of the American Dietetic Association: nutrition and lifestyle for a healthy pregnancy outcome. J Am Diet Assoc 2008; 108(3): 553-561.

5. Boggess KA, Edelstein BL. Oral health in women during preconception and pregnancy: implications for birth outcomes and infant oral health. Matern Child Health J 2006; 10(5 Suppl.): 169-174.

6. Bennett HA, Einarson A, Taddio A, et al. Prevalence of depression during pregnancy: systematic review. Obstet Gynecol 2004; 103(4): 698-709.

7. Floyd RL, Sobell M, Velasquez MM, et al. Project CHOICES Efficacy Study Group. Preventing alcohol-exposed pregnancies: a randomized controlled trial. Am J Prev Med 2007; 32(1): 1-10.

8. Lumley J, Oliver SS, Chamberlain C, et al. Interventions for promoting smoking cessation during pregnancy. Cochrane Database of Systematic Reviews. Cochrane Database Syst Rev 2009; 8(3): CD001055, doi: 10.1002/14651858.CD001055.pub3. 
9. Amezcua-Prieto $C$, Lardelli-Claret $\mathrm{P}$, Olmedo-Requena $\mathrm{R}$, et al. Compliance with leisure-time physical activity recommendations in pregnant women. Acta Obstet Gynecol Scand 2011; 90(3): 245-252.

10. Evenson KR, Barakat R, Brown WJ, et al. Guidelines for Physical Activity during Pregnancy: comparisons from around the world. Am $J$ Lifestyle Med 2014; 8(2): 102-121.

11. Brown W. The benefits of physical activity during pregnancy. J Sci Med Sport 2002; 5(1): 37-45.

12. Haskell WL, Lee IM, Pate RR, et al. American College of Sports Medicine; American Heart Association. Physical activity and public health: updated recommendation for adults from the American College of Sports Medicine and the American Heart Association. Circulation 2007; 116(9): 1081-1093.

13. DiNallo JM, Downs DS. The role of exercise in preventing and treating gestational diabetes: a comprehensive review and recommendations for future research. J Appl Biobehav Res 2007; 12(3-4): 141-177.

14. Buraczewska E, Sokołowska B, Mazurkiewicz B, et al. An analysis of the level of knowledge about diabetes among pregnant women. Fam Med Prim Care Rev 2016; 18(3): 225-229.

15. Sui Z, Dodd JM. Exercise in obese pregnant women: positive impacts and current perceptions. Int J Womens Health 2013; 5: 389-398.

16. Sorbye L, Klungsoyr K, Samdal O, et al. Pre-pregnant body mass index and recreational physical activity: effects on perinatal mortality in a prospective pregnancy cohort. BJOG 2015, doi: 10.1111/1471-0528.13290.

17. Lewis $B$, Avery $M$, Jennings $E$, et al. The effect of exercise during pregnancy on maternal outcomes: practical implications for practice. Am J Lifestyle Med 2008; 2(5): 441-455.

18. Juhl M, Andersen PK, Olsen J, et al. Physical exercise during pregnancy and the risk of preterm birth: a study within the Danish National Birth Cohort. Am J Epidemiol 2008; 167(7): 859-866.

19. Da Costa D, Ireland K. Perceived benefits and barriers to leisure-time physical activity during pregnancy in previously inactive and active women. Women Health 2013; 53(2): 185-202.

20. Connelly $\mathrm{M}$, Brown $\mathrm{H}$, van der Pligt $\mathrm{P}$, et al. Modifiable barriers to leisure-time physical activity during pregnancy: a qualitative study investigating first time mother's views and experiences. BMC Pregnancy Childbirth 2015; 15(1): 100, doi: 10.1186/s12884-015-0529-9.

21. Chasan-Taber L, Schmidt MD, Roberts DE, et al. Development and validation of a Pregnancy Physical Activity Questionnaire. Med Sci Sports Exerc 2004; 36(10): 1750-1760.

22. Ainsworth BE, Haskell WL, Whitt MC, et al. Compendium of Physical Activities: an update of activity codes and MET intensities. Med Sci Sports Exerc 2000; 32(9 Suppl.): 498-504.

23. Evenson KR, Wen F. Measuring physical activity among pregnant women using a structured one-week recall questionnaire: evidence for validity and reliability. Int J Behav Nutr Phys Act 2010; 7: 21, doi: 10.1186/1479-5868-7-21.

24. Harrison CL, Thompson RG, Teede HJ, et al. Measuring physical activity during pregnancy. Int J Behav Nutr Phys Act 2011; 8: 19, doi: 10.1186/1479-5868-8-19.

25. Teychenne M, Ball K, Salmon J. Associations between physical activity and depressive symptoms in women. Int J Behav Nutr Phys Act 2008; 5: 27, doi:10.1186/1479-5868-5-27.

26. Aittasalo $\mathrm{M}$, Pasanen $\mathrm{M}$, Fogelholm $\mathrm{M}$, et al. Validity and repeatability of a short pregnancy leisure time physical activity questionnaire. J Phys Act Health 2010; 7(1): 109-118.

27. Schmidt MD, Freedson PS, Pekow P, et al. Validation of the Kaiser Physical Activity Survey in pregnant women. Med Sci Sports Exerc 2006; 38(1): 42-50.

28. Ota E, Haruna M, Yanai $\mathrm{H}$, et al. Reliability and validity of the Vietnamese version of the Pregnancy Physical Activity Questionnaire (PPAQ). Southeast Asian J Trop Med Public Health 2008; 39(3): 562-570.

29. Matsuzaki M, Haruna M, Ota E, et al. Translation and cross-cultural adaptation of the Pregnancy Physical Activity Questionnaire (PPAQ) to Japanese. Biosci Trends 2010; 4(4): 170-177.

30. Matsuzaki M, Haruna M, Nakayama K, et al. Adapting the Pregnancy Physical Activity Questionnaire for Japanese pregnant women. J Obstet Gynecol Neonatal Nurs 2014; 43(1): 107-116.

31. Chandonnet N, Saey D, Alméras N, et al. French Pregnancy Physical Activity Questionnaire compared with an accelerometer cut point to classify physical activity among pregnant obese women. PLOS ONE 2012; 7(6): e38818, doi: 10.1371/journal.pone.0038818.

32. Tosun OC, Solmaz U, Ekin A, et al. The Turkish version of the pregnancy physical activity questionnaire: cross-cultural adaptation, reliability, and validity. J Phys Ther Sci 2015; 27(10): 3215-3221.

33. Çırak Y, Yılmaz GD, Demir YP, et al. Pregnancy physical activity questionnaire (PPAQ): reliability and validity of Turkish version. $J$ Phys Ther Sci 2015; 27(12): 3703-3709.

34. Kurpas D, Kern JB, Jacquet JP, et al. Programy promocji zdrowia i profilaktyki chorób - przykłady z Europy i USA. Fam Med Prim Care Rev 2015; 17(2): 152-156.

35. Biernat E, Stupnicki R, Gajewski A. Międzynarodowy Kwestionariusz Aktywności Fizycznej (IPAQ) - wersja polska. Wychow Fiz Sport 2007; 51(1): 47-54.

Tables: 2

Figures: 0

References: 35

Received: 23.10 .2016

Revised: 07.11.2016

Accepted: 21.11.2016

Address for correspondence:

Justyna Krzepota, PhD

Wydział Kultury Fizycznej i Promocji Zdrowia US

al. Piastów 40 b, blok 6

71-065 Szczecin

Polska

Tel.: +48 91 444-27-89

E-mail: justyna.krzepota@usz.edu.pl 